\title{
Links between tropical rainfall and North Atlantic climate during the last glacial period
}

\author{
Gaudenz Deplazes $^{1 \star}$, Andreas Lückge ${ }^{2}$, Larry C. Peterson ${ }^{3}$, Axel Timmermann ${ }^{4}$, Yvonne Hamann ${ }^{1}$, \\ Konrad A. Hughen ${ }^{5}$, Ursula Röhl ${ }^{6}$, Carlo Laj ${ }^{7}$, Mark A. Cane ${ }^{8}$, Daniel M. Sigman ${ }^{9}$ \\ and Gerald H. Haug ${ }^{1,10 \star}$
}

During the last glacial period, the North Atlantic region experienced pronounced, millennial-scale alternations between cold, stadial conditions and milder interstadial conditions-commonly referred to as Dansgaard-Oeschger oscillations-as well as periods of massive iceberg discharge known as Heinrich events ${ }^{1}$. Changes in Northern Hemisphere temperature, as recorded in Greenland ${ }^{2-4}$, are thought to have affected the location of the Atlantic intertropical convergence $z^{20 n e^{5,6}}$ and the strength of the Indian summer monsoon ${ }^{7,8}$. Here we use high-resolution records of sediment colour-a measure of terrigenous versus biogenic content-from the Cariaco Basin off the coast of Venezuela and the Arabian Sea to assess teleconnections with the North Atlantic climate system during the last glacial period. The Cariaco record indicates that the intertropical convergence zone migrated seasonally over the site during mild stadial conditions, but was permanently displaced south of the basin during peak stadials and Heinrich events. In the Arabian Sea, we find evidence of a weak Indian summer monsoon during the stadial events. The tropical records show a more variable response to North Atlantic cooling than the Greenland temperature records. We therefore suggest that Greenland climate is especially sensitive to variations in the North Atlantic system -in particular sea-ice extent-whereas the intertropical convergence zone and Indian monsoon system respond primarily to variations in mean Northern Hemisphere temperature.

Ice-core records from Greenland ${ }^{2,4}$ and sediment cores from the North Atlantic ${ }^{1,9}$ demonstrate that, over the course of the last ice age, colder conditions (stadials) alternated with warmer periods (interstadials) on timescales of several millennia. Some of the stadial periods identified in Greenland and other records coincided with massive meltwater discharges (Heinrich events) ${ }^{1}$ that originated from instabilities of the Northern Hemisphere ice sheets. Whereas the physical origin of Dansgaard-Oeschger oscillations still remains uncertain $^{10,11}$, their global teleconnections have been identified using climate models ${ }^{12,13}$ and palaeo-proxy data $a^{5,7,14-16}$. However, previous proxy records have lacked the resolution to fully capture the effect of millennial-scale glacial variability on interannual to decadal tropical rainfall variability.
In this study, we analysed sediments from the Cariaco Basin and the northeastern Arabian Sea in unprecedented resolution. Sediments from the Cariaco Basin on the northern shelf of Venezuela preserve detailed records of past tropical climate variability ${ }^{5,17,18}$. The Cariaco Basin sits within the present area of seasonal migration of the western Atlantic intertropical convergence zone (ITCZ), which controls the rainfall distribution over Central and northern South America (Supplementary Fig. S1). The migration of the ITCZ leads to seasonally varying inputs of terrigenous and biogenic components that are recorded as light/dark coloured laminations in the sediments at the sea floor ${ }^{17,19}$. The lamination depends on rainfall and productivity and therefore archives changes in climate variability. A sill separates the Cariaco Basin from the open Caribbean Sea. Limited deep-water renewal and oxygen demand driven by organic material remineralization result in present-day anoxic conditions leading to minimal bioturbation and preservation of sediment records with exceptional temporal resolution ${ }^{5,17-19}$. In the northeastern Arabian Sea, the seasonal cycle is dominated by the Indian monsoons. An intense oxygen minimum zone inhibits bioturbation, hence preserving annually laminated, high-resolution sediment archives of monsoon conditions $s^{7,8,20,21}$.

Here we report sediment total reflectance $\left(\mathrm{L}^{*}\right)$ measurements from the Cariaco Basin $\left(10^{\circ} 40.69^{\prime} \mathrm{N}, 64^{\circ} 58.29^{\prime} \mathrm{W}\right.$; water depth, $847 \mathrm{~m})$ and northeastern Arabian Sea $\left(23^{\circ} 07.34^{\prime} \mathrm{N}, 66^{\circ} 29.84^{\prime} \mathrm{E}\right.$; water depth of $571 \mathrm{~m}$ ) with a resolution of $\sim 70 \mu \mathrm{m}$ that can trace individual dark/light laminations (Figs 1 and 2 and Supplementary Figs S13 and S14). Variations in $\mathrm{L}^{*}$ on an annual to decadal scale reflect changes in the relative contributions of terrigenous and biogenic components with a further influence of redox state on a centennial to millennial scale. Sediments from the Cariaco Basin deposited during the Bølling-Allerød (B/A) interstadial and Holocene epoch are dark in colour (low $\mathrm{L}^{*}$ values), organic-carbonrich, and accumulated under anoxic conditions as indicated by their finely laminated nature $\mathrm{F}^{5,17}$ (Fig. 1). During the Younger Dryas event, the finely laminated sediments are lighter because of a greater relative input of biogenic carbonate and silica. During interstadials, dark, typically laminated sediments rich in organic carbon were deposited $^{5}$ (Fig. 2). In contrast, during the stadials, light coloured, intermittently laminated to homogeneous or bioturbated sediments

\footnotetext{
${ }^{1}$ Geological Institute, Department of Earth Sciences, ETH Zürich, 8092 Zürich, Switzerland, ${ }^{2}$ Bundesanstalt für Geowissenschaften und Rohstoffe, 30655 Hannover, Germany, ${ }^{3}$ Rosenstiel School of Marine and Atmospheric Science, University of Miami, Miami, Florida 33149, USA, ${ }^{4}$ IPRC, SOEST, University of Hawaii, Honolulu, Hawaii 96822, USA, ${ }^{5}$ Department of Marine Chemistry and Geochemistry, Woods Hole Oceanographic Institution, Woods Hole, Massachusetts 02543, USA, ${ }^{6}$ MARUM-Center for Marine Environmental Sciences, University of Bremen, 28359 Bremen, Germany, ${ }^{7}$ Laboratoire de Sciences du Climat et de l'Environment/IPSL, CEA/CNRS/UVSQ, 91198 Gif-sur-Yvette Cedex, France, ${ }^{8}$ Lamont-Doherty Earth Observatory of Columbia University, Palisades, New York 10964, USA, ${ }^{9}$ Department of Geosciences, Guyot Hall, Princeton University, Princeton, New Jersey 08544, USA, ${ }^{10}$ DFG Leibnitz Center for Earth Surface Process and Climate Studies, Institute for Geosciences, Potsdam University, Potsdam D-14476, Germany. *e-mail:gaudenz.deplazes@alumni.ethz.ch; gerald.haug@erdw.ethz.ch.
} 

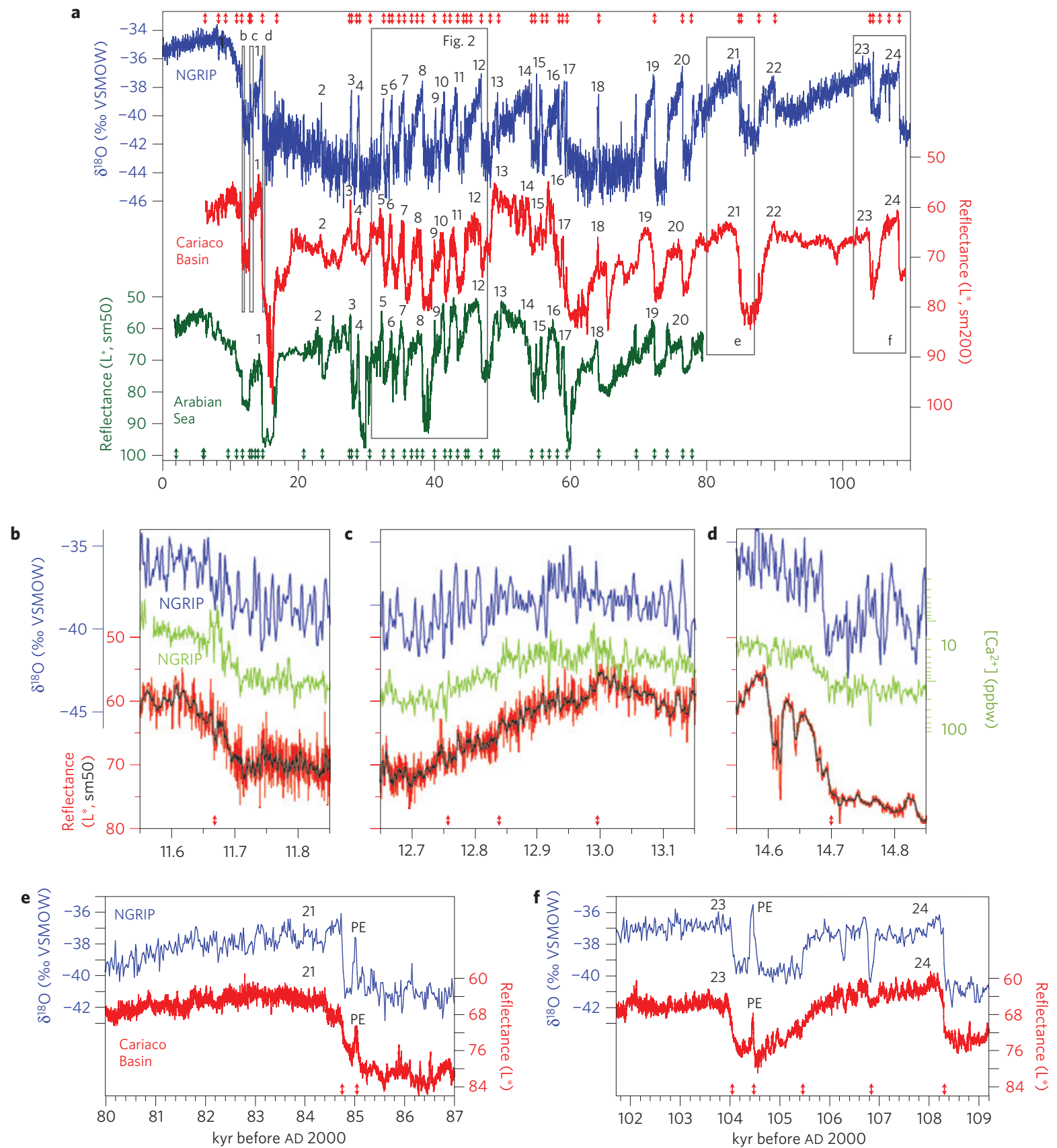

Figure 1 | Comparison of Cariaco Basin and Arabian Sea sediment total reflectance ( $L^{*}$ ) with $\delta^{18}$ O from NGRIP ice core. a, $L^{*}$ from Cariaco Basin (red, 200-point running mean), L* from Arabian Sea (green, 50-point running mean) and NGRIP $\delta^{18}$ O record (blue) $)^{2,4}$. b-d, Cariaco Basin L* (red, all data; black, 50-point running mean), NGRIP $\delta^{18} \mathrm{O}$ record (blue) and logarithmic plot of calcium concentration ([Ca ${ }^{2+}$ ], light green) ${ }^{22}$. e,f, L* (red) and NGRIP $\delta^{18} \mathrm{O}$ record (blue). Numbers indicate interstadial numbers; double-headed arrows indicate stratigraphic tie points. PE denotes precursor-type events ${ }^{3}$.

were deposited, indicating temporarily oxygenated conditions. The sediments from the Arabian Sea show a similar sedimentary pattern, with the Holocene, $\mathrm{B} / \mathrm{A}$ and interstadials characterized by the deposition of dark, laminated organic-carbon-rich strata ${ }^{21}$ and stadials with light-coloured, bioturbated sediments (Fig. 2).

Detailed comparison of the $\mathrm{L}^{*}$ record from the Cariaco Basin with high-resolution proxy records from the North Greenland Ice Core Project ${ }^{2,4,22}$ (NGRIP) for the glacial to Holocene transition shows a strong correspondence, especially at times of prominent climate transitions (Fig. 1b-d). During the last glacial period, both new $\mathrm{L}^{*}$ records mimic climate records from the higher latitude North Atlantic ${ }^{1,9}$ and Greenland ${ }^{2-4,22}$ (Figs 1 and 2 and Supplementary Fig. S6). By analogy with present-day seasonal variations ${ }^{8,17,19,20}$, and on the basis of the strong correspondence of the records, the $\mathrm{L}^{*}$ records are interpreted to indicate that warm Greenland interstadials are consistently associated with a more northerly annual position of the ITCZ over the tropical Americas and a stronger summer monsoon over India, supporting previous inferences from climate modelling ${ }^{13,23}$.

In addition to the millennial-scale interstadial/stadial events we can also identify in the $\mathrm{L}^{*}$ records the more elusive centennial-scale precursor-type events of the last glacial previously identified in Greenland ice cores ${ }^{3,4}$ and in European stalagmites ${ }^{24}$. Prominent precursor-type events have been described in ice records as peaks in $\delta^{18} \mathrm{O}$ and $\mathrm{CH}_{4}$ that preceded Interstadials 21 and 23 by about $100-300 \mathrm{yr}$ (ref. 3). The identification of these events for the first 


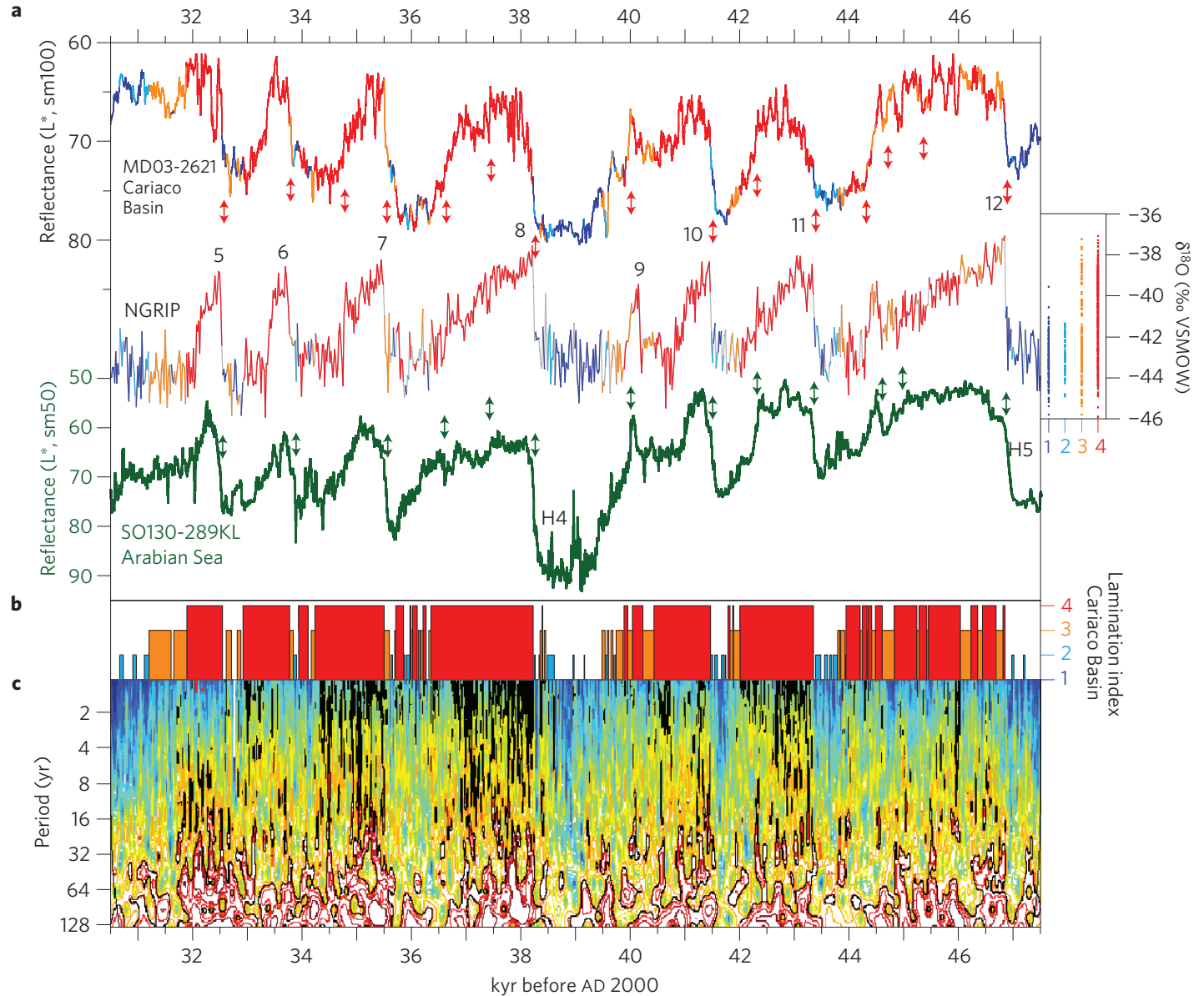

Figure 2 | Comparison of tropical and Greenland palaeoclimate variability. a, L* from the Cariaco Basin (100-point running mean), L* from the Arabian Sea (green, 50-point running mean) and the NGRIP $\delta^{18} \mathrm{O} \mathrm{record}^{2,4}$. Cariaco Basin and NGRIP records are coloured corresponding to a lamination index determined from high-resolution digital images of the Cariaco Basin sediments. A lamination index of 4 indicates continuous finely laminated sediments, whereas a lamination index of 1 indicates homogeneous or bioturbated sediments ${ }^{14}$. Numbers indicate interstadial numbers; double-headed arrows indicate stratigraphic tie points. The small plot on the right side shows the corresponding $\delta^{18} \mathrm{O}$ ranges in NGRIP at which the lamination indices occur. b, Lamination index from the Cariaco Basin. c, Morlet wavelet power spectrum of $\mathrm{L}^{*}$ from the Cariaco Basin ${ }^{30}$. Black contour lines indicate significance at a 95\% level.

time in tropical archives (Fig. 1e-f) documents their large-scale climatic footprints and the recording sensitivity of these tropical archives. Similar precursor-type events can also be recognized in the initial part of Marine Isotope Stage 3 in both the Cariaco Basin and Arabian Sea (Supplementary Fig. S9). The abrupt onset/end of the precursor-type events within decades might have been caused by the fast melting/growth of sea ice that in turn led to a rapid northward/southward shift of the ITCZ. The precursor-type events lasted long enough that the Atlantic meridional overturning circulation (AMOC) could have been involved. If so, the AMOC experienced major off-on-off pulses and was able to recover on decadal scales. Existing palaeo-AMOC records, however, generally lack the resolution to detect such changes in deep-water circulation and evaluate this hypothesis.

Although the correspondence of our tropical records with Greenland $\delta^{18} \mathrm{O}$ is compelling, further insights can be gleaned from where they differ. Similarly to the glacial-B/A transition (Fig. 1d), the interstadials recorded in the two marine sequences between 47.5 and 30.5 kyr before AD 2000 (Fig. 2) begin with an abrupt decrease in $\mathrm{L}^{*}$ values, corresponding to a sharp change from lighter coloured, often homogeneous or bioturbated to dark, laminated facies. After the initial abrupt step, it generally takes decades to centuries until the darkest sediment is reached; this dark colour is then maintained over centuries until a centennial-scale lightening at the beginning of the following stadial. These observations are largely insensitive to age model assumptions (Supplementary Fig. S7). In contrast, the NGRIP $\delta^{18} \mathrm{O}$ record has a much more pronounced sawtooth pattern, in which the highest $\delta^{18} \mathrm{O}$ values are reached immediately at the beginning of the interstadial and then decrease gradually through the interstadial and into the following stadial.

The correspondence between Cariaco Basin and Arabian Sea $\mathrm{L}^{*}$ records, speleothem $\delta^{18} \mathrm{O}$ records ${ }^{15,24}$ and high-resolution midlatitude Northern Hemisphere sea surface temperature (SST) records ${ }^{9}$ during the last glacial (Supplementary Fig. S6) suggests that the characteristic sawtooth structure of NGRIP $\delta^{18} \mathrm{O}$ variability is not a good template for tropical hydroclimate change. Furthermore, during cold climates, we observe that the dominant Heinrich events, such as Heinrich 4-6, can be traced easily as times of especially cold North Atlantic conditions ${ }^{9}$ and of anomalously weak summer monsoons in India and Asia ${ }^{15}$ compared with other DansgaardOeschger stadials (Supplementary Fig. S6). In contrast, Greenland $\delta^{18} \mathrm{O}$ shows rather constant climate conditions during Heinrich and non-Heinrich stadials.

Following previous studies ${ }^{25}$ we propose that the DansgaardOeschger sawtooth structure in Greenland $\delta^{18} \mathrm{O}$ is related to changes in sea-ice coverage in the Nordic seas and regional changes in precipitation. During interstadial/stadial transitions, sea-ice advances in the Nordic seas will affect large-scale atmospheric 

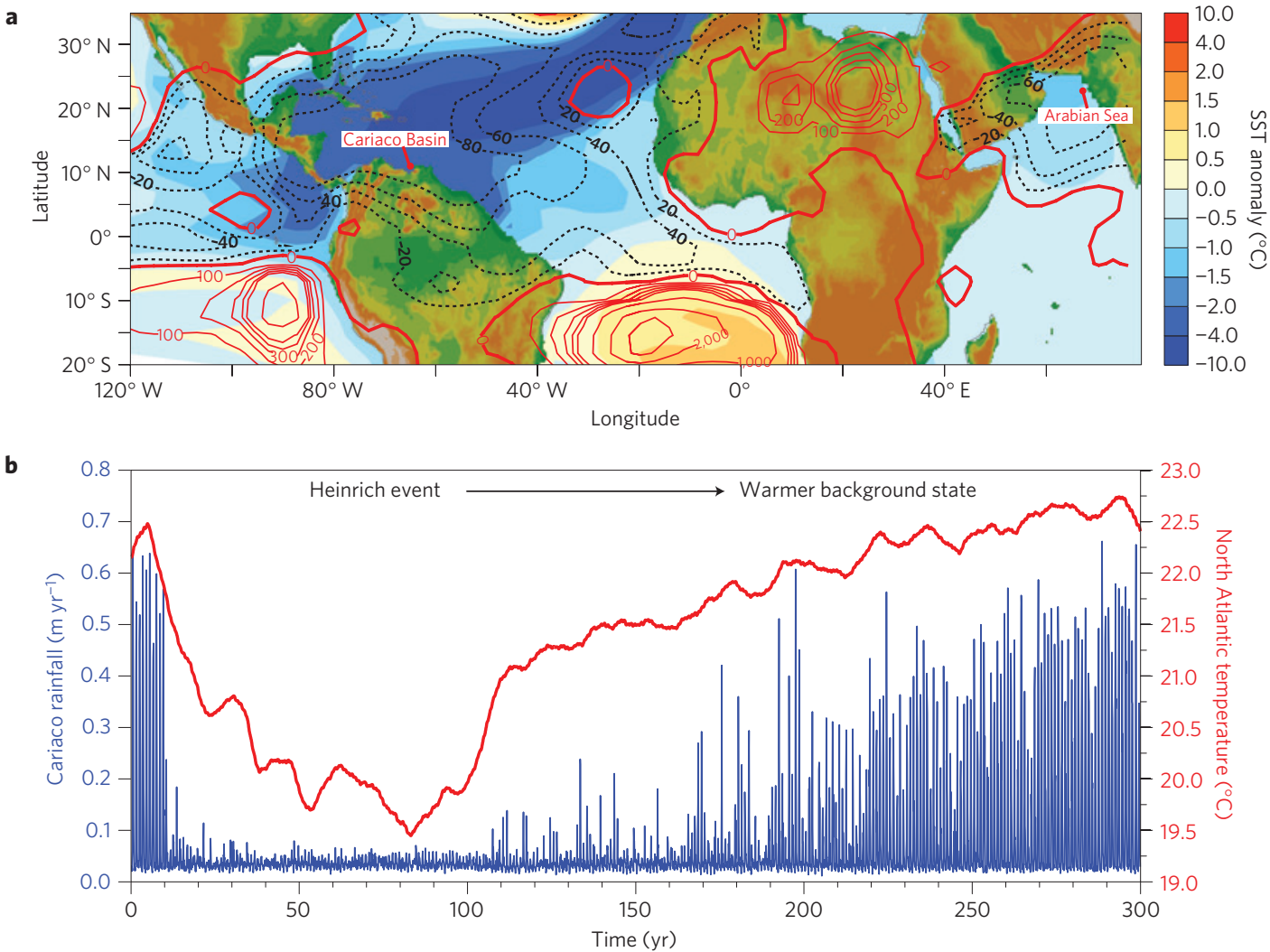

Figure 3 | Result of water-hosing simulation. a, SST anomaly (shading) simulated by the CCSM3 atmosphere-ocean general circulation model for a substantial weakening of the $\mathrm{AMOC}$ under glacial conditions compared with the Last Glacial Maximum control run ${ }^{28}$. Relative change in rainfall variance (\%; contours) during period of weakened AMOC and North Atlantic cooling. b. Simulated tropical temperature anomalies $\left({ }^{\circ} \mathrm{C}\right.$; red) and Cariaco Basin precipitation ( $\mathrm{m} \mathrm{yr}^{-1}$; blue) from the CCSM3 glacial water-hosing experiment. A northern North Atlantic freshwater forcing of 1.0 Sv was applied for years $0-100$.

circulation in the North Atlantic, causing an equatorward progression of cooling ${ }^{12}$, partly supported by air-sea interactions, such as the wind-evaporation SST feedback ${ }^{26}$, ocean dynamical adjustments ${ }^{23,27}$ and the advection of anomalously cold surface waters in the eastern branch of the subtropical gyre. The overall decadal adjustment time of tropical North Atlantic SSTs to high-latitude forcing may by itself lead to considerable smoothing of the tropical response to high-latitude signals. We reason further that as sea-ice progression reaches certain latitudes, Greenland $\delta^{18} \mathrm{O}$ values saturate, thus explaining why NGRIP $\delta^{18} \mathrm{O}$ registers relatively constant cold climate conditions during stadials, in contrast to the more complex stadial dynamics captured by SST reconstructions ${ }^{9}$ (Supplementary Fig. S6) and our tropical L* records. During interstadial periods, warming in the North Atlantic has two effects on tropical precipitation: as a result of higher air temperatures, the atmosphere can hold more moisture, which leads to increased precipitation in regions of mean convergence; weakening of the trade winds, in response to the reduced cross-equatorial SST gradient, leads to an anomalous convergence in the northern tropical Atlantic.

Complementing sediment colour, the occurrence of laminations in the Cariaco Basin shows remarkable sensitivity to climate. Under warm interstadial North Atlantic conditions, Cariaco sediments are distinctly laminated (Fig. 2a-b). The onset and initial intervals of the stadials are also mostly laminated. In contrast, homogeneous or bioturbated sediment is observed only in the coldest peak stadials, during Heinrich events, and at the end of the last glacial period (Fig. 2 and Supplementary Fig. S8).

Focusing on intervals in the Cariaco record with the most distinct lamination, we observe coherent changes in the high-frequency variation of $\mathrm{L}^{*}$. Interannual variability in $\mathrm{L}^{*}$ was significantly greater during interstadials than during stadials (Fig. 2, Supplementary Figs S10 and S11), even when changes in sedimentation rate are accounted for (Supplementary Fig. S12). Similar increases in variability of $\mathrm{L}^{*}$ can also be seen for timescales ranging from decades to centuries (Fig. 2c).

If the climatologic seasonal march of the ITCZ crosses the Cariaco Basin, and low oxygen conditions preserve sediment laminations, the $\mathrm{L}^{*}$ record captures interannual to multidecadal variations of hydroclimate. This sensitivity of $\mathrm{L}^{*}$ to interannual tropical variability should persist until the ITCZ migrates so far south that the seasonal forcing responsible for the lamination is minimized. This occurred during Heinrich events and peak stadials, when the western Atlantic ITCZ shifted far enough south that little rainfall reached the local river catchments that deliver terrigenous material to the Cariaco Basin and the trade winds were overhead nearly year-round.

To investigate tropical hydroclimate variability during Heinrich conditions, we analysed a water-hosing experiment that was conducted with the state-of-the art coupled general circulation model CCSM3 (ref. 28; Fig. 3). The idealized climate model experiment yields a substantial reduction in rainfall over the Cariaco Basin and the Arabian Sea (by about $80 \%$ at both sites), as well as a pronounced decrease in interannual rainfall variance. These changes are associated with a pronounced southward shift of the ITCZ and an overall weakening of the Indian summer monsoon, consistent with our data.

A southward shift of the ITCZ, in turn, probably impacts the AMOC by decreasing the freshwater influx to the North Atlantic ${ }^{23}$. Homogeneous or bioturbated sediments, indicative of 
increased oxygen availability, low productivity, reduced rainfall and a southerly position of the ITCZ, occurred mostly during the late stages of stadials or Heinrich events (see colouring in Fig. 2a). This is in line with the view that the stadials of the last ice age needed to reach some threshold in intensity and expanse before southward pressure on the ITCZ was adequate to salinify and densify the North Atlantic and thus to jump-start recovery of the AMOC (refs 23,29).

Our results highlight a robust mechanism that associates tropical rainfall and its annual to centennial variability with variations in North Atlantic climate. High-frequency variance in ultrahigh-resolution palaeo-records may provide a means to more quantitatively assess the processes that influence the mean position and variability of low-latitude frontal systems.

\section{Methods}

Material and age model. Colour reflectance logging has been used successfully as a proxy for changes in sediment composition and for correlation with other palaeo-proxy records ${ }^{5,7,17}$. The $\mathrm{L}^{*}$ record from the Cariaco Basin (MD03-2621; $10^{\circ} 40.69^{\prime} \mathrm{N}, 64^{\circ} 58.29^{\prime} \mathrm{W}$; water depth, $847 \mathrm{~m}$ ) spans the time period from $\sim 109.2$ to 6.4 kyr before AD 2000. The $\mathrm{L}^{*}$ record from the northeastern Arabian Sea (SO130-289KL; $23^{\circ} 07.34^{\prime} \mathrm{N}, 66^{\circ} 29.84^{\prime} \mathrm{E}$; water depth of $571 \mathrm{~m}$ ) spans the time period of $\sim 79.5-1.8 \mathrm{kyr}$ before AD 2000 (ref. 21). The first-order age models for MD03-2621 and SO130-289KL are based on cross-correlation to accelerator mass spectrometry (AMS) ${ }^{14} \mathrm{C}$-dated cores from the same regions $\mathrm{s}^{6,21}$, and for SO130-289KL on 20 new AMS ${ }^{14} \mathrm{C}$ dates (Supplementary Table S1). The age models were further fine-tuned by correlating the $\mathrm{L}^{*}$ records to the ice-core $\delta^{18} \mathrm{O}$ record of NGRIP using the extended Greenland Ice Core Chronology 2005 (GICC05) age scale $^{2,4,22}$ (Figs 1 and 2 and Supplementary Figs S2-S7). Further details of the data acquisition and the age model can be found in the Supplementary Information.

Water-hosing experiment. The water-hosing simulation was conducted with the coupled general circulation model CCSM3 (ref. 28). To mimic Heinrich conditions and a weakened AMOC, an idealized freshwater forcing of $1.0 \mathrm{~Sv}$ $\left(1 \mathrm{~Sv}=10^{6} \mathrm{~m}^{3} \mathrm{~s}^{-1}\right)$ was applied under Last Glacial Maximum boundary conditions for 100 years $^{28}$. In response, the AMOC weakens by about $80 \%$, and a $3{ }^{\circ} \mathrm{C}$ cooling in North Atlantic is simulated (Fig. 3).

Wavelet analysis. Before Morlet wavelet power spectrum analysis ${ }^{30}$, the $\mathrm{L}^{*}$ series from the Cariaco Basin was resampled to a 0.2 year resolution, filtered (band-pass filter of $0.5-256 \mathrm{yr}$ ) and standardized (zero mean and unit standard deviation; Fig. 3). The indicated $95 \%$ significance levels were calculated using a red-noise background spectrum.

Received 2 July 2012; accepted 27 December 2012; published online 10 February 2013

\section{References}

1. Bond, G. et al. Correlations between climate records from North Atlantic sediments and Greenland ice. Nature 365, 143-147 (1993).

2. Svensson, A. et al. A 60000 year Greenland stratigraphic ice core chronology. Clim. Past 4, 47-57 (2008).

3. Capron, E. et al. Millennial and sub-millennial scale climatic variations recorded in polar ice cores over the last glacial period. Clim. Past 6, 345-365 (2010).

4. Wolff, E. W., Chappellaz, J., Blunier, T., Rasmussen, S. O. \& Svensson, A. Millennial-scale variability during the last glacial: The ice core record. Quat. Sci. Rev. 29, 2828-2838 (2010).

5. Peterson, L. C., Haug, G. H., Hughen, K. A. \& Röhl, U. Rapid changes in the hydrologic cycle of the tropical Atlantic during the last glacial. Science 290, 1947-1951 (2000).

6. Hughen, K., Southon, J., Lehman, S., Bertrand, C. \& Turnbull, J. Marine-derived ${ }^{14} \mathrm{C}$ calibration and activity record for the past 50,000 years updated from the Cariaco Basin. Quat. Sci. Rev. 25, 3216-3227 (2006).

7. Schulz, H. \& von Rad, U. Correlation between Arabian Sea and Greenland climate oscillations of the past 110,000 years. Nature 393, 54-57 (1998).

8. Schulte, S. \& Müller, P. J. Variations of sea surface temperature and primary productivity during Heinrich and Dansgaard-Oeschger events in the northeastern Arabian Sea. Geo-Mar. Lett. 21, 168-175 (2001).

9. Martrat, B. et al. Four climate cycles of recurring deep and surface water destabilizations on the Iberian margin. Science 317, 502-507 (2007).

10. Wunsch, C. Abrupt climate change: An alternative view. Quat. Res. 65, 191-203 (2006).
11. Timmermann, A., Gildor, H., Schulz, M. \& Tziperman, E. Coherent resonant millennial-scale climate oscillations triggered by massive meltwater pulses. J. Clim. 16, 2569-2585 (2003).

12. Chiang, J. C. H. \& Bitz, C. M. Influence of high latitude ice cover on the marine Intertropical Convergence Zone. Clim. Dynam. 25, 477-496 (2005).

13. Zhang, R. \& Delworth, T. L. Simulated tropical response to a substantial weakening of the Atlantic thermohaline circulation. J. Clim. 18, 1853-1860 (2005).

14. Behl, R. J. \& Kennett, J. P. Brief interstadial events in the Santa Barbara basin, NE Pacific, during the past $60 \mathrm{kyr}$. Nature 379, 243-246 (1996).

15. Wang, Y. J. et al. A high-resolution absolute-dated Late Pleistocene monsoon record from Hulu Cave, China. Science 294, 2345-2348 (2001).

16. Shiau, L. J. et al. Warm pool hydrological and terrestrial variability near southern Papua New Guinea over the past 50 k. Geophys. Res. Lett. 38, L00F01 (2011).

17. Hughen, K. A., Overpeck, J. T., Peterson, L. C. \& Trumbore, S. Rapid climate changes in the tropical Atlantic region during the last deglaciation. Nature 380, 51-54 (1996).

18. Haug, G. H., Hughen, K. A., Sigman, D. M., Peterson, L. C. \& Röhl, U. Southward migration of the intertropical convergence zone through the Holocene. Science 293, 1304-1308 (2001).

19. Muller-Karger, F. et al. Annual cycle of primary production in the Cariaco Basin: Response to upwelling and implications for vertical export. J. Geophys. Res. 106, 4527-4542 (2001).

20. Lückge, A., Doose-Rolinski, H., Khan, A. A., Schulz, H. \& von Rad, U. Monsoonal variability in the northeastern Arabian Sea during the past 5000 years: Geochemical evidence from laminated sediments. Palaeogeogr. Palaeoclimatol. Palaeoecol. 167, 273-286 (2001).

21. Von Rad, U., Burgath, K-P., Pervaz, M. \& Schulz, H. in The Tectonic and Climatic Evolution of the Arabian Sea Region Vol. 195 (eds Clift, P. D., Kroon, D., Gaedicke, C. \& Craig, J.) 445-461 (Special Publications, Geological Society, 2002).

22. Steffensen, J. P. et al. High-resolution Greenland Ice Core data show abrupt climate change happens in few years. Science 321, 680-684 (2008).

23. Krebs, U. \& Timmermann, A. Tropical air-sea interactions accelerate the recovery of the Atlantic Meridional Overturning Circulation after a major shutdown. J. Clim. 20, 4940-4956 (2007).

24. Boch, R. et al. NALPS: a precisely dated European climate record 120-60 ka. Clim. Past 7, 1247-1259 (2011).

25. Li, C., Battisti, D. S. \& Bitz, C. M. Can North Atlantic Sea Ice anomalies account for Dansgaard-Oeschger climate signals? J. Clim. 23, 5457-5475 (2010)

26. Chiang, J. C. H., Cheng, W. \& Bitz, C. M. Fast teleconnections to the tropical Atlantic sector from Atlantic thermohaline adjustment. Geophys. Res. Lett. 35, L07704 (2008).

27. Chang, P. et al. Oceanic link between abrupt changes in the North Atlantic Ocean and the African monsoon. Nature Geosci. 1, 444-448 (2008).

28. Otto-Bliesner, B. L. \& Brady, E. C. The sensitivity of the climate response to the magnitude and location of freshwater forcing: Last glacial maximum experiments. Quat. Sci. Rev. 29, 56-73 (2010).

29. Schmidt, M. W., Vautravers, M. J. \& Spero, H. J. Rapid subtropical North Atlantic salinity oscillations across Dansgaard-Oeschger cycles. Nature 443 561-564 (2006).

30. Torrence, C. \& Compo, G. P. A practical guide to wavelet analysis. Bull. Am. Meteorol. Soc. 79, 61-78 (1998).

\section{Acknowledgements}

We thank the RV Marion Dufresne team, IPEV and the IMAGES programme for retrieving the Cariaco Basin cores during the PICASSO cruise. We are grateful to I. Hajdas and P. M. Grootes for performing the AMS ${ }^{14} \mathrm{C}$ measurements. This work was supported by the Deutsche Forschungsgemeinschaft (DFG) and the US National Science Foundation (NSF).

\section{Author contributions}

G.D. performed the reflectance analyses, interpreted the data and wrote the first version of the manuscript. A.L., L.C.P., C.L. and G.H.H. designed the study and helped organize the coring campaigns. Y.H. and U.R. supervised taking the pictures at the ETH Zürich and the MARUM, University of Bremen. A.T. analysed the water-hosing simulation. D.M.S and M.A.C. contributed to the interpretation of the data. All the authors discussed the results and provided significant input to the final manuscript.

\section{Additional information}

Supplementary information is available in the online version of the paper. Reprints and permissions information is available online at www.nature.com/reprints. Correspondence and requests for materials should be addressed to G.D. or G.H.H.

\section{Competing financial interests}

The authors declare no competing financial interests. 